\title{
Long-term effects of thinning and mixing on stand spatial structure: a case study of Chinese fir plantations
}

\author{
Yuanfa $\mathrm{Li}^{(1-2)}$, \\ Junmo Xu ${ }^{(1)}$, \\ Hongxiang Wang ${ }^{(1)}$, \\ You Nong ${ }^{(3)}$, \\ Guo Sun ${ }^{(1)}$, \\ Sufang $\mathrm{Yu}^{(1)}$, \\ Liangning Liao ${ }^{(1)}$, \\ Shaoming Ye ${ }^{(1)}$
}

The regular planting and periodic harvesting of a single tree species are features of plantations, which are associated with a reduction of biodiversity. Such plantations are strongly encouraged to be converted into mixed forests. However, the spatial structure dynamics of plantations during the conversion process are poorly understood. In subtropical regions, thinned forest of Chinese fir (Cunninghamia lanceolata [Lamb.] Hook.) and mixed forest of Chinese fir and Michelia macclurei Dandy are considered two ideal modes of plantation management. In this study, we analyzed the spatial structure dynamics of two forest stands and their six main tree populations over a rotation of 27 years, using spatial point analyses. We found that Chinese fir and $M$. macclurei had a regular distribution pattern (scale, $r=0-1 \mathrm{~m}$ ) in the early stages of planting (1993), and Chinese fir maintained this pattern after experiencing self-thinning and selective cutting. In addition, non-planted tree species (i.e., natural regeneration of late-seral species, NRLSS) displayed significantly intraspecific clumping, which resulted in the distribution patterns of the forest stands changing from regular to aggregated $(r=0-5.5,1-20 \mathrm{~m})$, and the species distribution of mixed forest changed from random to clumped $(r=0-20 \mathrm{~m})$. Moreover, during the management period (1993-2018), individuals were significantly differentiated in terms of size, and some small trees in the thinned forest were aggregated together. For the NRLSS, the diameter at breast height was randomly distributed $(r=0-20 \mathrm{~m})$. Furthermore, Chinese fir and M. macclurei were separated at $r=0-1 \mathrm{~m}$ in the planting stage, but any pair of the six main populations in the thinned forest and mixed forest were randomly correlated over a rotation. Finally, the nearest neighbor distance of the stands became shorter after conversion, while the values for Chinese fir increased. After 25 years, the mixed plantation and the thinned plantation had a complex spatial structure. They develop towards natural forests and could be used as a template for future plantation management.

Keywords: Chinese Fir, Distribution Pattern, Mixed Forest, Plantation, Spatial Correlation, Thinning

\section{Introduction}

With the global decrease in natural forest resources, plantations play an increasingly important role in easing the conflict between wood supply and demand, increasing incomes from forestry, and protecting the natural environment (Taki et al. 2010, Plath et al. 2011, Liu et al. 2018). The traditional model of plantation management is intensive, i.e., a monoculture with regular rows. This has widely been adopted to provide the maximum growing space for any tree, with the planting regime designed as far as possible to avoid competition in the early growth stage. The management process mainly focuses on nonspatial structure indicators that are closely related to wood harvest (e.g., stand density, diameter at breast height $[\mathrm{DBH}]$, tree height, basal area or stand stock - Li et al. 2014). This management model might be appropriate for a short-term rotation forest, but it has been widely criticized for neglecting biodiversity, and conversion into mixed forest has been proposed to address this (Felton et al. 2010, Wu et al. 2018, Liu et al. 2018,
Wang et al. 2019). At the same time, a growing number of studies, including those conducted in natural/semi-natural forest plantations, have indicated that the spatial structure of forest stands (e.g., spatial correlation, tree location, species mixture, size differentiation, and other indicators related to the distance between trees) is equally important for tree growth and community stability (Crecente-Campo et al. 2009, Potvin \& Dutilleul 2009, Li et al. 2014, Hui et al. 2019). More attention should be given to the spatial structure of plantations, particularly in the cultivation process.

Thinning and mixing are often used in forest management to transform the spatial structure of monoculture plantations ( $\mathrm{Ye}$ et al. 2018, Wang et al. 2019, Zhang et al. 2019, Harrington 2020). Thinning directly reduces stand density, improves environmental conditions, promotes litter decomposition and growth of residuals, and increases stand volume and understory regeneration (Sheng 2001, Li et al. 2014, Kitagawa et al. 2017, Wu et al. 2018). Mixing 
takes advantage of the complementation/ differences in species demands for habitat (e.g., light dependence - Pretzsch et al. 2016, Liu et al. 2018), nutrient consumption (Yao et al. 2019), and growth rhythms (Feng et al. 1988, Chen et al. 1990, Sheng \& Xue 1992). Both thinning and mixing can have a profound impact on forest dynamics, and are conducive to the formation of forest structure and species diversity (Kint et al. 2003, Felton et al. 2010, Taki et al. 2010, Wu et al. 2018, Harrington 2020). Most previous studies have explored the characteristics of plant species diversity, growth (Sun et al. 2015, Ozbayram \& Ciçek 2018), carbon storage (Zhang et al. 2019), photosynthesis ( $\mathrm{Li}$ et al. 2017a), soil nutrient cycles, microbial diversity (Feng et al. 1988, Sheng \& Xue 1992, Wang et al. 2010, Ye et al. 2018), and small animals such as insects and birds (Felton et al. 2010, Taki et al. 2010) in the period immediately after plantations were thinned or mixed. Only a few studies have considered the spatial structure of plantations at stand level (Crecente-Campo et al. 2009, Potvin \& Dutilleul 2009, Zheng et al. 2017). Detecting the influence of thinning and mixing on the spatial structure of plantations on a long-term scale could achieve a more suitable management method.

Chinese fir (Cunninghamia lanceolata [Lamb.] Hook - Taxodiaceae) is one of the most widely planted coniferous species in subtropical regions $\left(102^{\circ}-122^{\circ} \mathrm{E}, 21^{\circ} 41^{\prime}-33^{\circ}\right.$ $41^{\prime} \mathrm{N}$ ), accounting for $24 \%$ of China's plantation area and $6.1 \%$ of the global plantation area (Feng et al. 1988, Liu et al. 2018). However, with the increase in planting area and generations of continuous planting of Chinese fir in the collective forest regions of South China, the accumulation of toxic substances in soil, the decrease in the speed of nutrient biochemical cycles, the reduction of the microbial community and its activity, and the aggravation of pests and diseases, there has been a decline in forest productivity in many areas (Chen et al. 1990, Sheng \& Xue 1992). Some plantations have become typical old-aged and small-sized stands, which seriously threaten the sustainability of Chinese fir plantations. It is believed that establishing mixed forests of Chinese fir and broad-leaved species is an ideal way to solve this problem (Cai et al. 2007, Liu et al. 2018). Many studies have considered a move away from unreasonable modes of planting (e.g., monocultures and continuous planting) and harvesting (e.g., clear cutting), and have used test methods such as closing access to a mountain for afforestation (Cai et al. 2007), extending the rotation time (Lin et al. 2001, Lin \& Huang 2001), thinning (a popular management method in some locations Xiong et al. 1995, Sheng 2001, Sun et al. 2015, Zhang et al. 2019), and mixing Chinese fir and other indigenous species, e.g., M. macclurei, Mytilaria laosensis Lec., Manglietia yuyuanensis Law, Schima superba Gardn. \& Champ., Liquidambar formosana Hance, Fokienia hodginsii (Dunn) Henry et Thomas, and Phyllostachys heterocycla (Carr.) Mitford cv. Pubescens Mazel ex H.de leh (Feng et al. 1988, Zheng et al. 1998, Liu et al. 2018, Zhang et al. 2019). Chinese fir and $M$. macclurei mixed forests are a high productivity forest model (Feng et al. 1988, Chen et al. 1990). However, we know little about the spatial structure of the mixed forest and Chinese fir thinned forest, particularly their dynamics over a rotation (e.g., 20 years).

In our experience, postponing the year of harvesting will likely promote the occurrence of other tree species (hereafter, natural regeneration of late-seral species, NRLSS). This may reduce the distances between nearest neighbors (hypothesis 1). Thinning will likely also change the distribution pattern of the planted trees. Therefore, we assumed that the degree of regularity of the distribution pattern in the thinned forest and mixed forest will decrease over a rotation (hypothesis 2). NRLSS in the stands might then be affected by the superior species from the upstory (Felton et al. 2010, Kitagawa et al. 2017), i.e., a nonrandom correlation (hypothesis 3) should be found between NRLSS and the planted species (Chinese fir and $M$. macclurei). We used data collected from the planting area of Chinese fir to test these hypotheses.

\section{Materials and methods}

\section{Overview of sub-compartment \\ management}

Our study site was located in Binqiao Township, Longzhou County, Pingxiang City, southwest China. It was part of the Experimental Center of Tropical Forestry of the Chinese Academy of Forestry and was close to the boundary with Lanson, north Vietnam. This region has a typical subtropical climate, with abundant rainfall and heat resources. Its average annual temperature is $19.5-21.5^{\circ} \mathrm{C}$ and average annual rainfall is around $1200-1500 \mathrm{~mm}$. The terrain is dominated by hills, with the highest peak in the region being $1046 \mathrm{~m}$ a.s.l. in the Daqing Mountains, where the relative elevation difference is $916 \mathrm{~m}$ (Cai et al. 2007, Sun et al. 2015). The soil at the study site is a weakly acidic mountain red soil, with a thickness of more than $80 \mathrm{~cm}$. Plantation management and scientific research have been conducted in this area for nearly half a century, and Chinese fir and Masson pine (Pinus massoniana Lamb.) are the main afforestation species. The management unit of a Chinese fir plantation in this area is based on the sub-compartment system (also called a forest stand or alpha level), i.e., all practices taken in a sub-compartment are exactly the same. Many plantations have been established and harvested for 2-3 generations. Scientific research has mainly concentrated on mixed forest management, monoculture plantation thinning, close-to-nature forest management, and soil nutrient cycling (Ming et al. 2014, Sun et al. 2015, Huang et al. 2017, Ming et al. 2018).

\section{Plot establishment}

According to previous studies (Feng et al. 1988, Chen et al. 1990), a Chinese fir and $M$. macclurei mixed forest was cultivated in the $4^{\text {th }}$ sub-compartment of the $3^{\text {rd }}$ compartment on a mountainside location $\left(106^{\circ}\right.$ $42^{\prime} 16^{\prime \prime} \mathrm{E}, 22^{\circ} 18^{\prime} 09^{\prime \prime} \mathrm{N}$ ) in the spring of 1991. Similar-sized Chinese fir and M. macclurei seedlings (height $\approx 50 \mathrm{~cm}$ ) were randomly mixed in a 6:1 ratio and then planted. The planting row spacing was

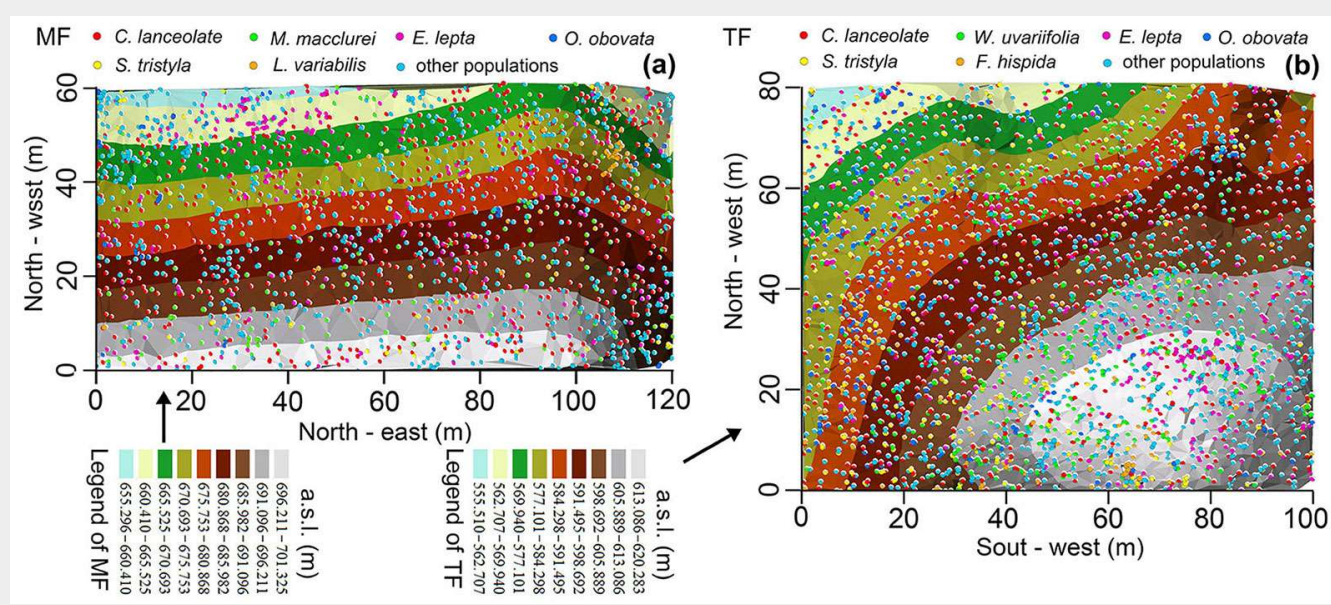

Fig. 1 - The terrain of Chinese fir plantations and tree location patterns in the sub-compartments. The mixed forest (MF) was located on a large, gentle slope, while the thinned forest (TF) was located on the top of a hill. The colored points represent the six main tree species and the background colors indicate height above sea level (a.s.I.), which gradually decreased as the color changed from white to light blue. 
kept as consistent as possible. The primary density was about 2000 plants ha-1, with an $87 \%$ survival rate after 2 years (1993). During the same period, a monoculture of Chinese fir was cultivated in the $3^{\text {rd }}$ sub-compartment of the $6^{\text {th }}$ compartment $\left(106^{\circ} 42^{\prime}\right.$ $48^{\prime \prime} \mathrm{E}, 22^{\circ} 17^{\prime} 44^{\prime \prime} \mathrm{N}$ ). It was about $900 \mathrm{~m}$ from the mixed forest, with the same planting pattern and preservation rate. A thinning was applied in 2008, reducing tree density by $26 \%$, with a total of 631 trees $(\mathrm{DBH} \geq 9 \mathrm{~cm})$ removed, after which there was no human-made disturbance. Two rectangular fixed plots, with areas of $100 \times 80$ $\mathrm{m}$ and $120 \times 60 \mathrm{~m}$, in the above sub-compartments were established in 2018-2019 (Fig. 1). First, a total station (model NTS$372 \mathrm{R}_{10}$, South Surveying \& Mapping Company, Guangzhou, China) was used to confirm the outline border and locations ( $x, y$, $z$ ) of living trees $(\mathrm{DBH} \geq 1 \mathrm{~cm}$, height of tree $\geq 1.3 \mathrm{~m}$ ), coarse dead wood (DBH $\geq 1 \mathrm{~cm}$, length/height $\geq 1.3 \mathrm{~m}$ ), and stumps. Then species were identified and living trees were tagged.

A total of 1909 and 3084 living trees, and 558 and 857 dead trees, belonging to 79 and 58 species, were investigated in the mixed forest and thinned forest, respectively. Among them, Chinese fir, M. macclurei, Evodia lepta (Spreng.) Merr., Saurauia tristyla DC., Ficushispida Linn., Wendlandia uvariifolia Hance, Litsea variabilis Hemsl., and Oreocnide obovata (C. H. Wright), and Merr. var. mucronata C. J. Chen were the main species. The coverage of the understory herb in both plots (thinned forest, mixed forest) was greater than $95 \%$. They were mainly made up of Woodwardia japonica (L. f) Sm., Dryopteris atrata (Kunze) Ching, Angiopteris fokiensis $\mathrm{Hi}$ eron., Costus speciosus (Koen.) Smit, Musa balbisiana Tutch., and Amischotolype hispida (Less. \& Rich.) Hon. (Tab. S1 in Supplementary material).

\section{Data analyses}

After conversion into a mixed forest, the structure of Chinese fir stands will become more complex. The pair correlation function (PCF) can combine the individual distribution of trees and the distance between them to reveal the ecological process behind the distribution pattern (He \& Duncan 2000, Pommerening 2002, Getzin et al. 2006, Law et al. 2009, Wiegand \& Moloney 2014, Omelko et al. 2018). The spatial scale of this study was limited to the stand level, which implies that the role of habitat heterogeneity in ecological processes might be very limited. Therefore, complete spatial randomness (CSR) was directly taken as the null model of the univariate distribution of the PCF, $g(r)$ (Omelko et al. 2018), to analyze the distribution patterns of the thinned forest and mixed forest stands, their six main populations, and the cutting wood. At the same time, random labeling was taken as the null model of $g_{11}(r)-g_{22}(r)$ to detect any changes in the distribution pattern before and after management (Wiegand \& Moloney 2014). The independence of components was adopted as the null model of the bivariate distribution of PCF, $g_{12}(r)$ (Baddeley \& Turner 2005), to analyze the spatial correlation between Chinese fir and $M$. macclurei in the mixed forest at the early planting stage, and the spatial correlation between any two populations $(N \geq 40)$ in the mixed forest and thinned forest over a rotation (2018). The mark correlation function was used to analyze the spatial distribution of tree species in the mixed forest at the initial stage of planting and species in the mixed forest and thinned forest in 2018 (Pommerening 2002, Baddeley \& Turner 2005, Wiegand \& Moloney 2014). The mark variogram function was used to analyze the spatial distribution of DBH in the thinned forest and mixed forest stands and their six main populations over a rotation (2018 - CrecenteCampo et al. 2009, Pommerening \& Särkkä 2013). In the process of point pattern analyses, the Monte Carlo (MC) method was used to simulate the observed values at $r=$
0-20 m 199 times and preliminarily confirm the random interval, then a goodness of fit was applied to test and correct the result of the simulation, to eliminate and type I errors (Wiegand \& Moloney 2014). In addition, $D^{k}(r)$ was used to analyze the cumulative distribution of the nearest neighbor distance (NND) of the thinned forest and mixed forest and their six main populations ( $k=1,2,4,6,8,10$, and 12 -Omelko et al. 2018). Data analyses were conducted using the "spatstat" package (Baddeley \& Turner 2005) of the $R$ software environment ( $R$ Development Core Team 2019).

\section{Results}

\section{Distribution patterns and tree marks at}

the stand level

At the beginning of planting (1993), the thinned forest and mixed forest had a very similar distribution pattern, i.e., a significant regular distribution at a small scale $(r$ = 0-1 $\mathrm{m}$ ), a slightly aggregated distribution at $r=1-6 \mathrm{~m}$, and a random distribution at other scales (Fig. 2a, Fig. 2d). In 2018, the mixed forest was clustered at small scales $(r=0-5.5 \mathrm{~m})$ and randomly distributed at large scales ( $r=6-20 \mathrm{~m}$ - Fig. $2 \mathrm{~b})$, but the thinned forest was clustered at almost all scales (Fig. 2e). During the management period (1991-2018), the changes in the distribution pattern were mainly concentrated at $r=0-1.0 \mathrm{~m}$, ranging from an intensive regular distribution to an aggregated distribution (Fig. 2C, Fig. 2f). The species richness of the mixed forest increased from 2 to 58 , and its spatial distribution changed from random (Fig. 2g) to a strong aggregation (Fig. 2h). The species richness of the thinned forest increased from 1 to 79 , indicating a high concentration of species (Fig. $2 j)$. The DBH of the mixed forest were distributed almost randomly (Fig. 2i), while small trees in the thinned forest presented an aggregated pattern ( $r=0-7 \mathrm{~m}-$ Fig. $2 \mathrm{k}$ ). The majority of trees cut from the thinned forest had a clumped distribution (Fig. 2l).
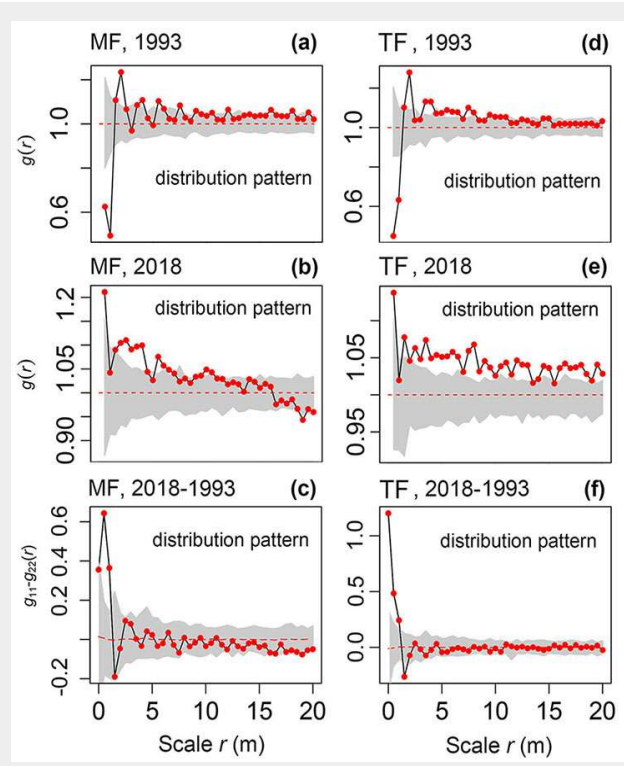
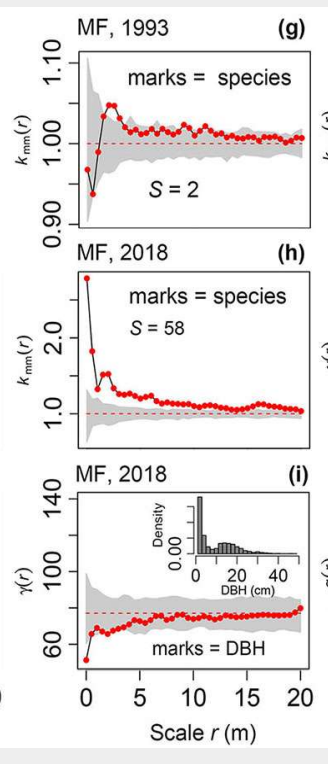
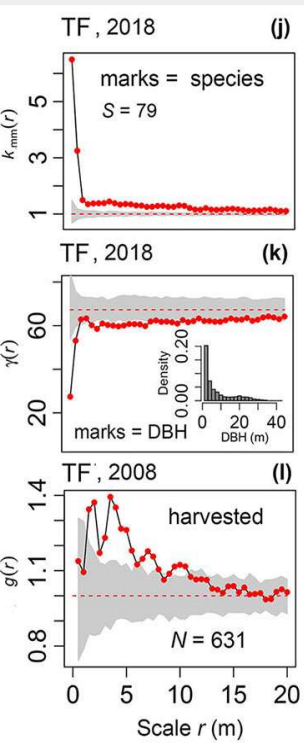

(j) marks in the Chinese fir mixed forest (MF) and thinned forest (TF) at the stand level ( $g-k)$ and distribution pattern of the whole stands based on the complete spatial randomness (CSR) null model (a, b, d, e, i). The difference in the distribution patterns of the MF and TF during the management period based on the random labeling null model and the distribution pattern of the harvested woods based on the CSR null model. $S$ and $N$ are species richness and the number of individuals, respectively. The gray color represents the $95 \%$ Monte Carlo simulation area and the dashed red line is the expected value, while the black solid line with red dots is the observed value. 

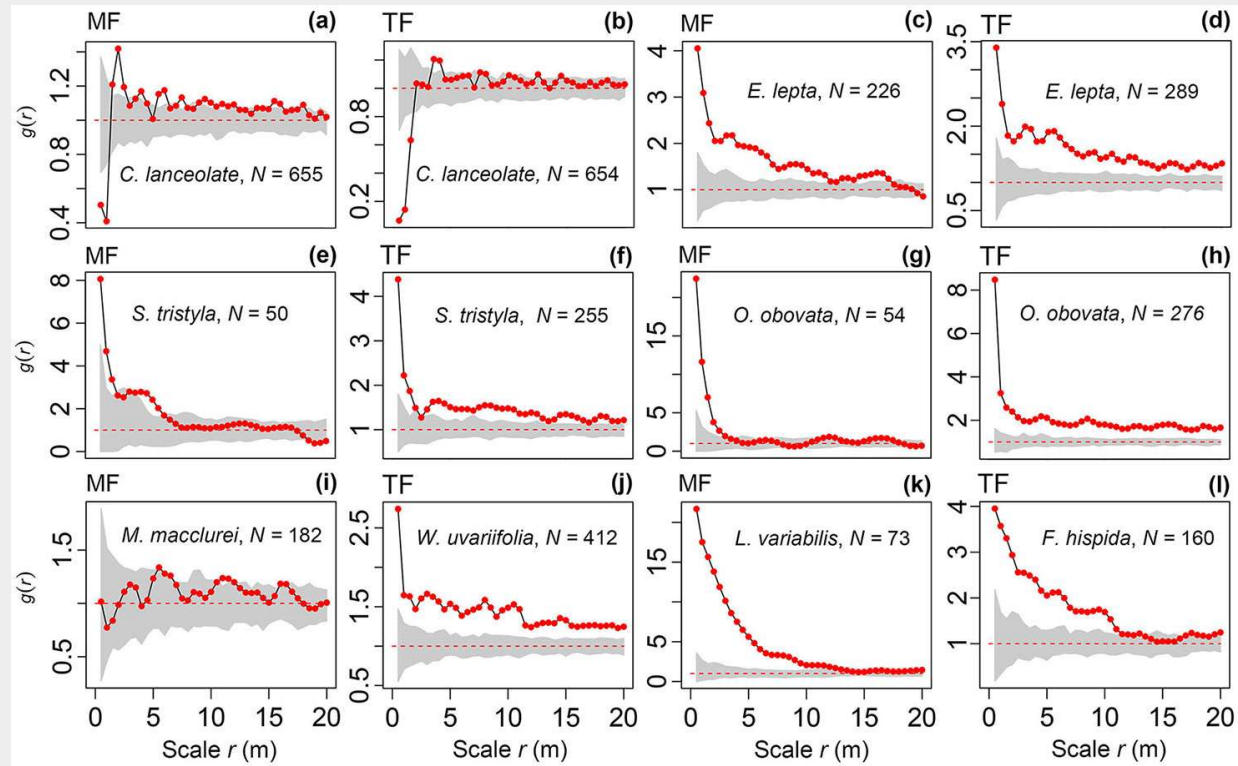

(d) Fig. 3 - Distribution patterns of the main populations in the Chinese fir thinned forest (TF) and mixed forest (MF) over a rotation based on the complete spatial randomness (CSR) null model. The gray color represents the $95 \%$ Monte Carlo simulation area and the black solid line marked with red dots is the observed value, while the red dashed line is the expect value of 1 . $\mathrm{N}$ is the number of individuals.
Distribution patterns of the main tree populations

During the management period (19912018), although some of the Chinese fir in the thinned forest and mixed forest suffered self-thinning and cutting (54.8\% and $44.4 \%$, respectively), the stands planted largely retained the distribution pattern at planting (Fig. 3a, Fig. 3b). However, $M$. macclurei in the mixed forest had a random distribution at most scales $(r=0-20 \mathrm{~m}-\mathrm{Fig}$. 3i), which was slightly different from the distribution at planting (see Fig. S1c in Supplementary material). In both the thinned forest and mixed forest, E. lepta, O. obovata, and S. tristyla belonged to the NRLSS, with a large number of individuals. Each species differed in abundance in both stands, but displayed a similar aggregation pattern (Fig. 3C to Fig. 3h). In addition, W. uvariifolia and $F$. hispida in the thinned forest and $L$. variabilis in the mixed forest also displayed a strong aggregation (Fig. $3 j$ to Fig. 3l).

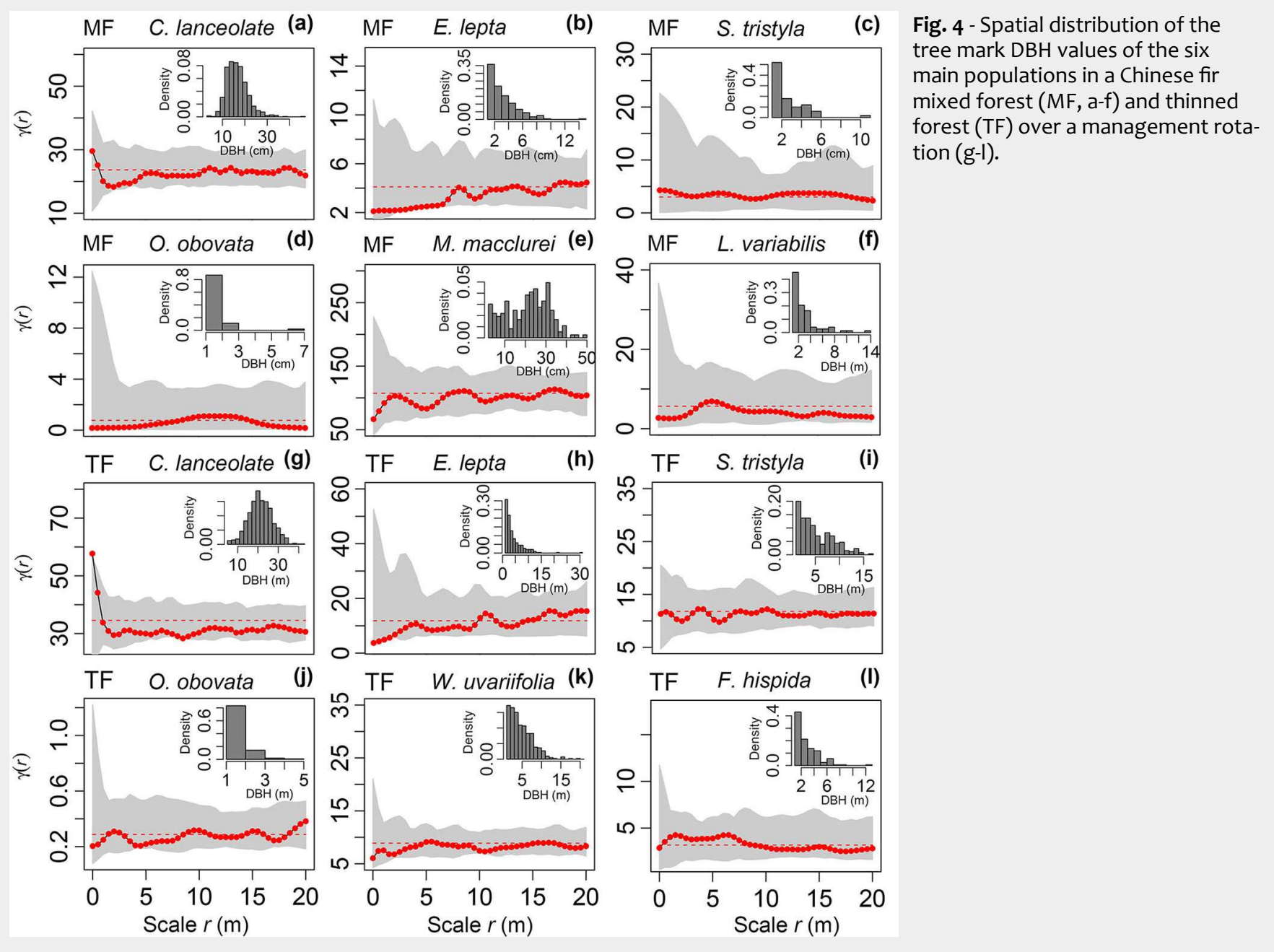


Fig. 5 - Spatial correlations among the main populations in the Chinese fir mixed forest (MF) and thinned forest (TF) over a rotation. The blue dots represent a random or no correlation, the green dots represent a positive correlation, and the red dots represent a negative correlation. (NRLSS): natural regeneration of late-seral species.

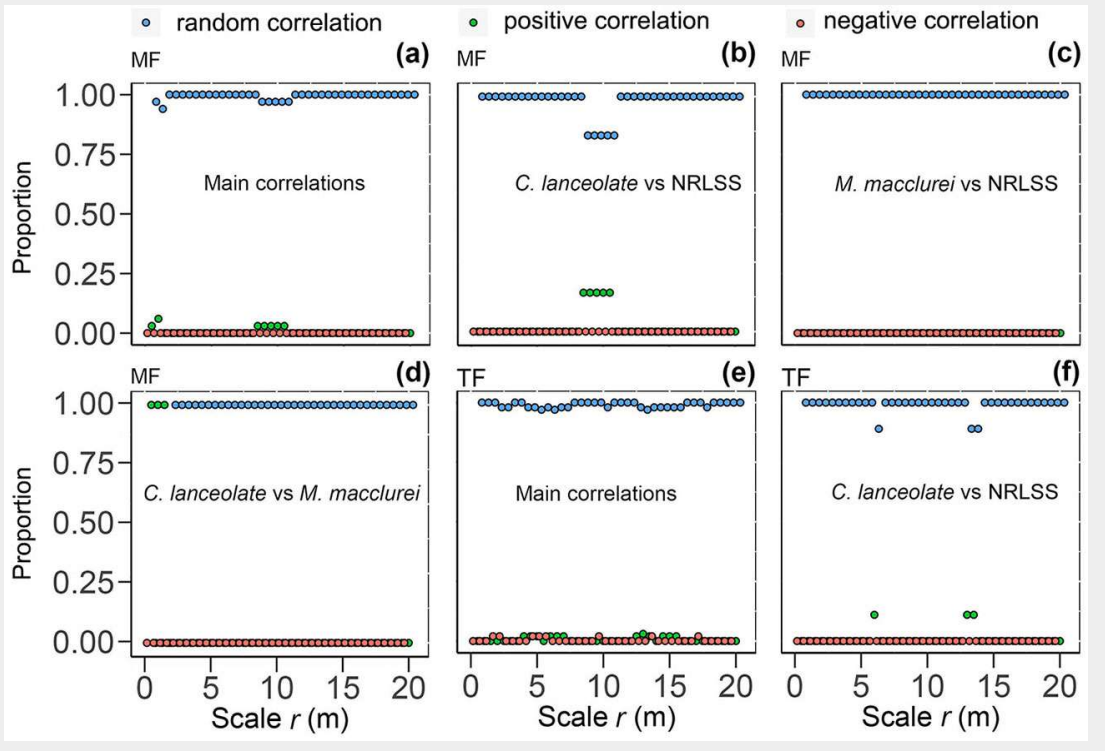

\section{DBH of the six main populations}

$\mathrm{DBH}$ of the six populations in the mixed forest at $r=0-2 \mathrm{~m}$ (Fig. $4 \mathrm{~h}$ ).

forest and thinned forest was calculated. Although these tree species were different in terms of their diameter classes, their DBH was very similar. The majority of them had a random distribution pattern (Fig. 4a to Fig. 4l). Only some populations were close to the lower edge of the MC simulation interval at some scales, for example, $E$. lepta in the mixed forest at $r=2-6 \mathrm{~m}$ (Fig. $4 \mathrm{~b}), 0$ obovata in the mixed forest at $r=0-$
$5.5 \mathrm{~m}$ (Fig. 4d), and E. lepta in the thinned

\section{Spatial correlations of the thinned \\ forest and mixed forest}

The interspecific spatial correlations of 36 pairs of the main populations $(N \geq 40)$ in the mixed forest were calculated and their probability distribution was determined. It was found that the interspecific correlations were random overall, with only a few (3-6\%) positive correlations at $r=0.5,1$, and
8.5-10.5 m (Fig. 5a). Chinese fir was also randomly correlated with the NRLSS (7 pairs), displaying a slight positive correlation at $r=8.5-10.5 \mathrm{~m}$ (Fig. 5b). However, $M$. macclurei was randomly correlated with all of the NRLSS (7 pairs) at each scale ( $r=0$ $20 \mathrm{~m}$ - Fig. 5C). Chinese fir and $M$. macclurei were also clumped to each other at $r=0.0$ $1.5 \mathrm{~m}$, and maintained a random correlation at the other scales ( $r=1.5-20 \mathrm{~m}-$ Fig. $5 \mathrm{~d})$. In the thinned forest, more than $97 \%$ of the correlations among 66 pairs of any species
Fig. 6 - The nearest neighbor distances (NND) of the six main populations and Chinese fir thinned forest (TF) and mixed forest (MF) stands before (1993) and after (2018) management $(k=1,2,4,6,8$, and 12).

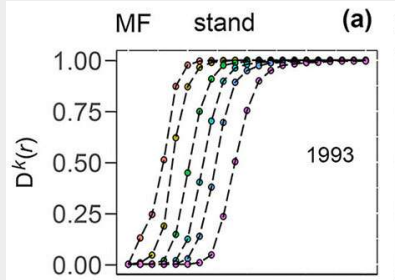

(a) MF stand

(b) MF C. lanceolate

(c)
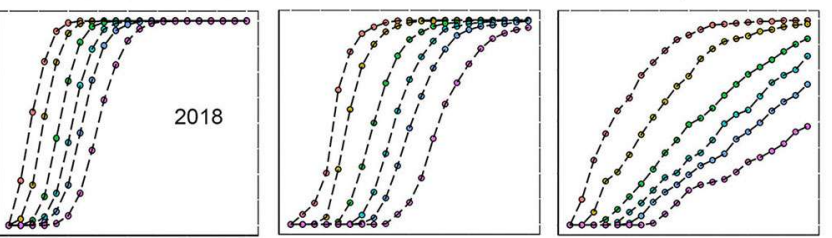

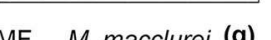

MF L. variabilis (h)
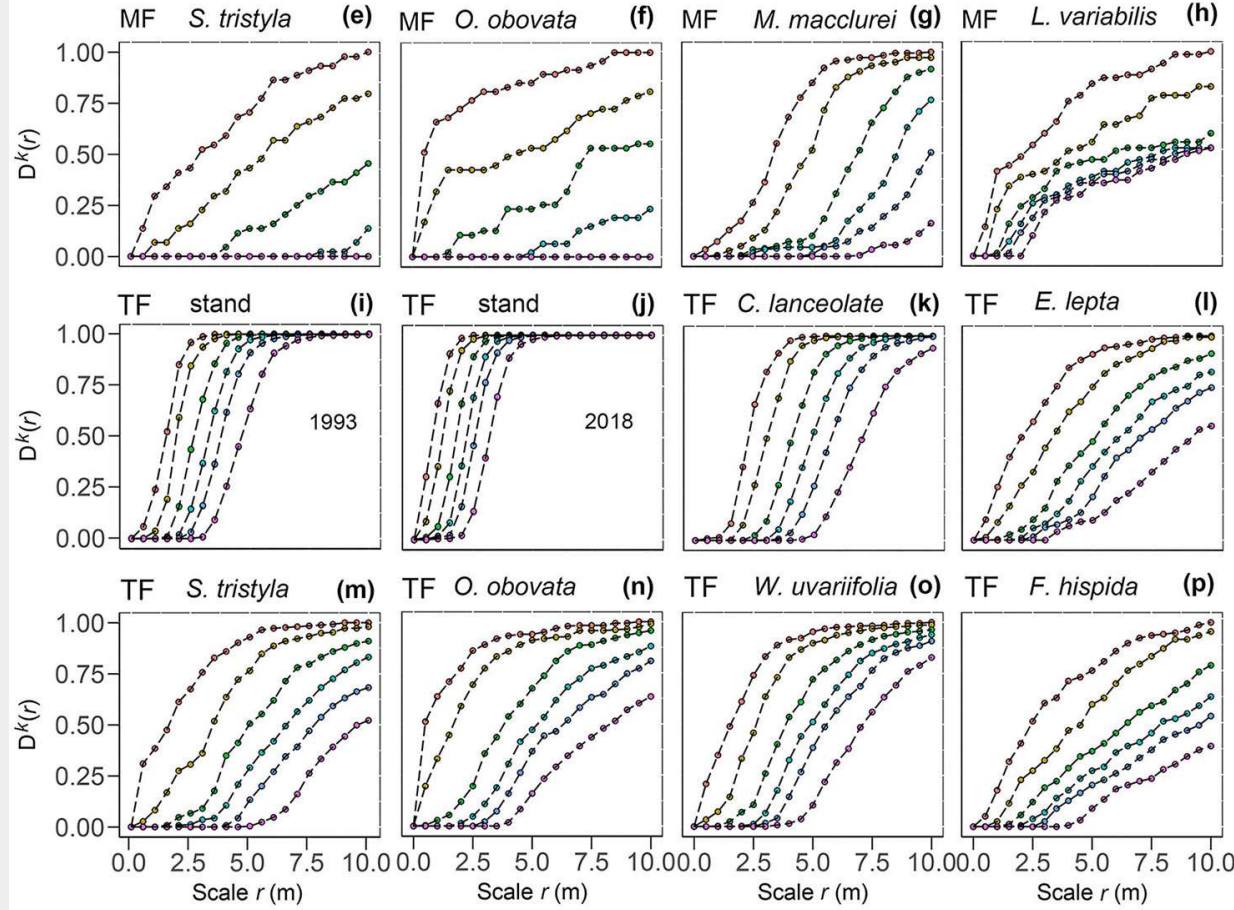

Scale $r(m)$

Scale $r(m)$

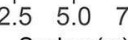

Scale $r(m)$

$\begin{array}{ll}5 & 5.0 \\ \text { Scale } r(\mathrm{~m})\end{array}$ 
were positive, but only a slight clumping occurred at some scales (Fig. 5e). Except for $r=6$ and 13-13.5 m, Chinese fir and the NRLSS (11 pairs) had a random correlation (Fig. 5f).

\section{Distribution of the NND}

The cumulative distribution of the NND ( $k$ $=1,2,4,6,8$, and 12) of the mixed forest and thinned forest stands at the planting stage (1993) and over a rotation (2018) was calculated. After a rotation (2018), the distances between nearest neighbors became shorter and the probability of occurring at the $k^{\text {th }}$ distance increased (Fig. 6a vs. Fig. $6 \mathrm{~b}$, Fig. $6 \mathrm{i}$ vs. Fig. $6 \mathrm{j}$ ). The probability of Chinese fir occurring in the mixed forest was slightly higher than that in thinned forest over the same distance (Fig. $6 \mathrm{c}$ vs. Fig. 6k). Evodia lepta in the mixed stand and thinned stand had a similar NND distribution (Fig. 6d vs. Fig. 6l). Both S. tristyla and 0 . obovate were relatively dispersed in the mixed forest, but were concentrated in the thinned forest (Fig. 6e vs. Fig. 6m; Fig. $6 \mathrm{f}$ vs. Fig. 6n). There were $12 \mathrm{~W}$. uvariifolia, $F$. hispida, and $L$. variabilis trees distributed at a small distance from each other $(r=0-4.5$ and $0-2 \mathrm{~m}$ ), and their probability of occurring at the $k^{\text {th }}$ distance increased with the increase in scale (Fig. 6o, Fig. 6p, Fig. 6h). The NND values for $M$. macclurei indicated that the trees were relatively dispersed (Fig. 6g) and their distribution did not significantly differ from that at the planting stage (1993 - Fig. S2 in Supplementary material).

\section{Discussion}

Influence of thinning and mixing on the distribution pattern of plantations

Traditional stand description methods can no longer meet the needs of multiage forest management (Kint et al. 2000, Li et al. 2012, 2014, Ye et al. 2018). There is increasing evidence that the spatial pattern of tree locations and sizes should be considered alongside the traditional assessments of stand descriptions to provide guidance for multi-objective forest management, particularly when plantations are being converted into more natural stands to meet a desired management objective (Reed \& Burkhart 1985, Pommerening 2002, Crecente-Campo et al. 2009). Regular planting has been widely used in monoculture forest (Kuuluvainen et al. 1996, Kint et al. 2003, Pretzsch et al. 2016). At the initial stage of planting, the thinned forest and mixed forest had a regular distribution of trees at small scales (Fig. 2a, Fig. 2d), disclosing plantation characteristics rather than the interaction between trees. After thinning for 10 years, the NND of Chinese fir increased (Fig. 6i vs. Fig. 6k), but the distribution pattern was almost unchanged (Fig. 2d vs. Fig. 3b), indicating that the distribution pattern of Chinese fir changed slightly due to medium and low intensity thinning. The changes in the distribution pattern of Chinese fir in the mixed forest were also small (Fig. 3a vs. Fig. S1b in Supplementary material), further suggesting that the Chinese fir population and its regular pattern will last for a long time. Some studies have suggested that stripe thinning has an important effect on the spatial locations of planted trees, and its intensity is closely related to the degree that a plot trends toward a random distribution pattern (Crecente-Campo et al. 2009). However, it has been shown that thinning intensity based on structured forest management has little effect on the plantation distribution of Larix principis-rupprechtii Mayr. (Ye et al. 2018). Therefore, we believe that the distribution patterns of the remaining trees are closely related to the thinning modes and intensity of harvesting. Furthermore, when considering the timescale, the distribution patterns of the remaining trees are also related to their self-thinning and regeneration. For example, the distribution pattern of $M$. macclurei changed from slightly regular to completely random, mainly due to tree death and natural regeneration (Fig. 4e). Chinese fir cannot achieve regeneration in the understory (Lin et al. 2001, Liu et al. 2018), and therefore no small trees were present (Fig. 4a).

With the prolongation of succession time, the occurrence of the NRLSS reduced the NND of the stands (Fig. 6a vs. Fig. 6b, Fig. $6 \mathrm{i}$ vs. Fig. $6 \mathrm{j}$ ). They not only displayed a strong aggregation pattern (Fig. 3c-h, Fig. 3j, Fig. 3l), but also resulted in an aggregated distribution in the thinned forest and mixed forest (Fig. 2e, Fig. 2b), and greatly increased the degree of interspecific isolation (Fig. 2 g vs. Fig. 2h, Fig. 2j). This is consistent with our hypotheses 1 and 2, but the formation mechanism of the aggregation patterns in the thinned forest, and mixed forest stands may be different. It has been proposed that thinning provides suitable habitats for the growth of vegetation in forest gaps or the understory in the short-term (Sheng 2001, Pommerening 2002, Sun et al. 2015, Wu et al. 2018, Zhang et al. 2019), and this small scale heterogeneity is critical to seedling survival and growth (Plath et al. 2011). By contrast, the spatial distribution of branches, leaves, and roots of Chinese fir mixed forest is different from that of pure forest (Sheng \& Xue 1992), which slowly changes the environment and affects the development process of the NRLSS (Pretzsch et al. 2016, Trentini et al. 2017). This may explain why the thinned forest contained more species than the mixed forest (Cole et al. 2008, Trentini et al. 2017) and they differed in abundance, point distribution, and size differentiation (Fig. S3, Fig. S4, Fig. S5, Tab. S1 - Supplementary material). The differences may be characterized by randomness (Kitagawa et al. 2017). The thinned forest and mixed forest formed three layers of trees, shrubs, and grass in the vertical direction (Fig. S5a, $\mathrm{S} 5 \mathrm{~b})$, which was consistent with the characteristics of an overmature plantation (31 years) in the central production area of Chinese fir in Fujian Province, China (Lin et al. 2001), and these forests had a high species diversity.

\section{Influence of thinning and mixing on plantation tree size}

Tree sizes reflect the process of stand development and the degree of external disturbance, and are often used to evaluate or support forest management (Lexerød \& Eid 2006, Li et al. 2014, Hui et al. 2019). Many studies have suggested that thinning simultaneously promotes both preservation and undergrowth (Potvin \& Dutilleul 2009, Sun et al. 2015, Ozbayram \& Çiçek 2018, Ye et al. 2018, Zhang et al. 2019), but the relationship between the two is not clear. In this study, Chinese fir and NRLSS in the thinned forest were present in different layers (Fig. S5C, Fig. S5d in Supplementary material), and the saplings were clustered (Fig. 2k). In a Pinus sylvestris L. artificial forest, Crecente-Campo et al. (2009) found that self-thinning and growth did not change the spatial distribution of tree sizes in the short term (4 years), but intensive thinning resulted in tree sizes in the stands becoming negatively correlated. This would explain the differences in tree size distribution in the thinned forest and mixed forest (Fig. 2i, Fig. 2k), indicating that thinning expands the growth rate of trees in the upper and lower layers. However, this phenomenon may be temporary. In an old-growth Chinese fir plantation (56 years), the tree growth declined after thinning and some hardwood trees entered the main forest layer, forming a highly mixed forest (Lin et al. 2001). Other studies have also suggested that the degree of tree size autocorrelation in virgin forests is very low (Kuuluvainen et al. 1996).

The tree sizes of the six main species in the thinned forest and mixed forest were randomly distributed (Fig. 4a to Fig. 4l). This may be because the main competition within stands was also stratified, which was apparent from the diameter classes. The normal diameter of Chinese fir in the thinned forest implies intensively intraspecific competition (Fig. 4g). The partially right skewed distribution of the diameter classes of Chinese fir in the mixed forest suggests interspecific competition caused by M. macclurei (Fig. 4a). With the exception of small trees, the diameter classes of $M$. macclurei in the mixed forest also indicated intraspecific competition. The random correlation between planted trees and NRLSS further indicated that competition was occurring (Fig. 5a, Fig. 5e). The strong intraspecific aggregation may be an important reason for the random distribution of tree sizes in the lower layer, i.e., there was density dependence (He \& Duncan 2000, Wiegand \& Moloney 2014). Some studies have also suggested that the distribution of small trees in artificial forests is a result of competition (Pommerening 2002). Comparing a series of 30- to 57-year-old 
pine/oak secondary forests, Li et al. (2017b) found that a stable DBH differentiation formed early (before 30 years), and concluded that the distribution pattern was related to but not strongly affected by $\mathrm{DBH}$ differentiation. Potvin \& Dutilleul (2009) also found this tendency in artificial forests. Individuals of the same species were generally smaller in the mixed forest than in the thinned forest (Tab. S1 in Supplementary material), reflecting the impact of the model of forest management on tree sizes (Wan et al. 2019, Zhang et al. 2019).

Influence of thinning and mixing on the spatial correlations of plantation trees

In natural forests, spatial correlations are commonly used to explore species coexistence mechanisms (Getzin et al. 2006, Wiegand \& Moloney 2014, Petritan et al. 2014). By contrast, the spatial correlation between Chinese fir and $M$. macclurei in the mixed forest at the beginning of planting (1993) was a feature of human actions (Fig. S1d). The planting patterns strongly limited the development of relationships among trees. Even over a full rotation period (27 years), species planted were only clumped to each other at a small scale, and the original correlation was preserved at most scales (Fig. 5d). This transformation may be the result of Chinese fir self-thinning and the seeds of $M$. macclurei falling and emerging successfully (Fig. 4e), which is in line with the changes in the distribution pattern and number of $M$. macclurei individuals present during the management period (1993-2018 - Fig. S1C vs. Fig. 3i). When the planted $M$. macclurei reached physiological maturity its shade-tolerant seedlings were able to regenerate and grow in the understory (Feng et al. 1988). At the same time, the relationships between the planted species (Chinese fir, $M$. macclurei) and NRLSS were very weak (Fig. 5a-f), indicating that the upper reserved populations had little influence on NRLSS, which is inconsistent with our hypothesis 3. The random correlation may be related to the distribution pattern preserved by the planted populations (Fig. 3a, Fig. 3b). The continuous regular distribution resulted in there being many similar niches in each stage of stand development from young to middleaged and then to mature forest, which is conducive to the aggregation of conspecifics (Fig. 3c-h, Fig. 3j-l; Fig. 6d-h, Fig. 6l-p) and to the random correlation of heterospecies entering the stands (Fig. 5a, Fig. 5e), suggesting that intraspecific competition is the main force driving stand succes sion. Most previous studies have also found that intraspecific correlations are more intense than interspecific correlations (Getzin et al. 2006, Adler et al. 2018). In two previous studies (Lin et al. 2001, Harrington 2020), after thinning, hardwood trees in a Chinese fir and longleaf pine ( $\mathrm{Pi}$ nus palustris) flourished in stages, indirectly supporting our viewpoint.

\section{Conclusions}

The conversion of plantations into mixed forests has become very popular, but there have been few successes. Chinese fir has a long history of cultivation in China. Many stands have been clear-felled and have undergone several crop rotations, resulting in a significant decrease in biodiversity, stability, sustainability, and ecosystem services. The conversion of even-aged pure forest to multi-aged mixed forest may have many ecological and economic benefits, and also completely change the structure, composition, and function of the stand. Although some conversion measures have been adopted, only short-term stand dynamics have been evaluated. On the basis of previous experiments, we explored the influence of thinning and mixing on the spatial distribution, interspecific correlation, mark characteristics, and NND of Chinese fir plantations. The mechanisms by which thinning and mixing operate on plantation conversion may be different, but our case shows that they significantly promoted species richness and spatial heterogeneity at the stand level, suggesting that the transformation of Chinese fir to mixed forest was successful and may serve as a model for future plantation management. Thinning might be more suitable for the management of Chinese fir plantations than mixed forest. The thinned forest provided more timber than the mixed forest, suggesting that thinning may be a popular local harvesting method. The rotation timescale after local thinning needs to be extended and the NRLSS also need protection in the thinning process. The effects of thinning and mixing on the growth of plantations and the improvement of the natural environment need to be further monitored and evaluated.

\section{List of abbreviations}

- MF: mixed forest

- TF: thinned forest

- NRLSS: natural regeneration of late-seral species

- DBH: diameter at breast height

- PCF: pair correlation function

- CSR: complete spatial randomness

- NND: nearest neighbor distance

- MC: Monte Carlo

\section{Acknowledgements}

This paper was financially supported by Guangxi special fund project for innovation-driven development (AA 17204087-8). PhD student Xianyu Yao, master students Deyi Zhu, Ji'an He, Haipeng Yang and undergraduates Xian Li, Yongzhen Huang joined data collection. Lihua Lu from the Experimental Center of Tropical Forestry, Chinese Academy of Forestry participated in test design and plot establishment.

\section{References}

Adler PB, Smull D, Beard KN, Choi RT, Furniss T, Kulmatiski A, Meiners JM, Tredennick AT, Veblen KE (2018). Competition and coexistence in plant communities: intraspecific competition is stronger than interspecific competition. Ecology Letters 21: 1319-1329. - doi: 10.1111/ele.13098 Baddeley A, Turner R (2005). spatstat: an R package for analyzing spatial point patterns. Journal of Statistical Software 12 (6): 1-42. - doi: 10.186 37/jss.v012.io6

Cai D, Lu L, Jia H, He R (2007). The influence of closing for afforestation on vegetation diversity restoration under Chinese fir plantation. Forest Research 20 (3): 319-327.

Chen C, Zhang J, Zhou C, Zheng H (1990). Researches on improving the quality of forest land and the productivity of artificial Cunninghamia lanceolata stands. Journal of Applied Ecology 1 (2): 97-106. [online] URL: http://en. cnki.com.cn/Article_en/CJFDTotal-YYSB1990020 oo.htm

Cole H, Newmaster S, Lanteigne L, Pitt D (2008). Long-term outcome of precommercial thinning on floristic diversity in north western New Brunswick, Canada. iForest 1: 145-156. - doi: 10.3832/iforo470-0010145

Crecente-Campo P, Pommerening A, RodríguezSoalleiro $R$ (2009). Impacts of thinning on structure, growth and risk of crown fire in a $\mathrm{Pi}$ nus sylvestris L. plantation in northern Spain. Forest Ecology and Management 257: 19451954. - doi: 10.1016/j.foreco.2009.02.009

Felton A, Lindbladh M, Brunet J, Fritz O (2010). Replacing coniferous monocultures with mixed-species production stands: an assessment of the potential benefits for forest biodiversity in northern Europe. Forest Ecology and Management 260: 939-947. - doi: 10.1016/j.foreco.20 10.06.011

Feng Z, Chen C, Zhang J, Zeng S, Luo R, Chen W (1988). A coniferous broad-leaved mixed forest with higher productivity and ecological harmony in subtropics study on mixed forest of Cunninghamia lanceolata and Michelia macclurei. Acta Phytoecologica et Geobotanica Sinica 12 (3): 165-180. [online] URL: http://en. cnki.com.cn/Article_en/CJFDTotal-ZWSB198803 ooo.htm

Getzin S, Dean C, He F, Trofymow JA, Wiegand K, Wiegand T (2006). Spatial patterns and competition of tree species in a Douglas-fir chronosequence on Vancouver Island. Ecography 29: 671-682. - doi: 10.1111/j.2006.0906-7590.04675.x Harrington TB (2020). Long-term effects of thinning and woody control on longleaf pine plantation development, understory abundance, and tree damage from an ice storm. Forest Ecology and Management 459 (5): 117846. - doi: 10.1016/j.foreco.2019.117846

He F, Duncan RP (2000). Density-dependent effects on tree survival in an oldgrowth Douglas fir forest. Journal of Ecology 88: 676-688. - doi: 10.1046/j.1365-2745.2000.00482.X

Huang $X$, Liu S, You Y, Wen Y, Wang H, Wang J (2017). Microbial community and associated enzymes activity influence soil carbon chemical composition in Eucalyptus urophylla plantation with mixing $\mathrm{N}_{2}$-fixing species in subtropical China. Plant and Soil 414 (1-2): 199-212. - doi: 10.1007/s11104-016-3117-5

Hui G, Zhang G, Zhao Z, Yang A (2019). Methods of forest structure research: a review. Current Forestry Reports 5: 142-154. - doi: 10.1007/s40 72 5-019-00090-7 
Kint V, Lust N, Ferris R, Olsthoorn AFM (2000). Quantification of forest stand structure applied to Scots pine (Pinus sylvestris L.) forests. Inves tigación Agraria: Sistemas y Recursos Fore stales 1: 147-163. [online] URL: http://www.re searchgate.net/publication/28052668

Kint V, Meirvenne MV, Nachtergale L, Geudens G, Lust N (2003). Spatial methods for quantifying forest stand structure development: a comparison between nearest-neighbor indices and variogram analysis. Forest Science 49 (1): 3649. [online] URL: http://academic.oup.com/for estscience/article/49/1/36/4617467

Kitagawa R, Ueno M, Masaki T (2017). Thinning affects understorey tree community assembly in monoculture plantations by facilitating stochastic immigration from the landscape. Applied Vegetation Science 20: 673-682. - doi: 10.1111/avsc.12327

Kuuluvainen T, Penttinen A, Leinonen K, Nygern M (1996). Statistical opportunities for comparing stand structural heterogeneity in managed and primeval forests: an example from boreal spruce forest in southern Finland. Silva Fennica 30 (2-3): 315-328. - doi: 10.14214/sf.a9243

Law R, Illian J, Burslem DFRP, Gratzer G, Gunatilleke CVS, Gunatilleke IAUN (2009). Ecological information from spatial patterns of plants: insights from point process theory. Journal of Ecology 97 (4): 616-628. - doi: 10.1111/j.1365-274 5.2009.01510.x

Lexerød NL, Eid T (2006). An evaluation of different diameter diversity indices based on criteria related to forest management planning. Forest Ecology and Management 222: 17-28. - doi: 10.1016/j.foreco.2005.10.046

Lin K, Huang B (2001). Studies on $\beta$-diversity index of undergrowth plant in Chinese fir plantation. Biodiversity Science 9 (2): 157-161. [online] URL: http://www.biodiversity-science.net/EN/ abstract/abstract8029.shtml

Lin K, Yu X, Huang B, He Z (2001). Dynamical characteristics of undergrowth plant diversity in Chinese fir plantations. Chinese Journal of Applied Environmental Biology 7 (1): 13-19. [online] URL: http://en.cnki.com.cn/Article_en/CJF DTotal-YYHS200101002.htm

Li Y, Hui G, Zhao Z, Hu Y (2012). The bivariate distribution characteristics of spatial structure in natural Korean pine broad-leaved forest. Journal of Vegetation Science 23 (6): 1180-1190. doi: 10.1111/j.1654-1103.2012.01431.X

Li Y, Ye S, Hui G, Hu Y, Zhao Z (2014). Spatial structure of timber harvested according to structure-based forest management. Forest Ecology and Management 322: 106-116. - doi: 10.1016/j.foreco.2014.02.042

Li Y, Hui G, Yu S, Yao X, Ye S (2017a). Nearest neighbour relationships in Pinus yunnanensis var. tenuifolia forests along the Nanpan River, China. iForest 10: 746-753. - doi: 10.3832/ifor24 05-010

Li R, Yang Q, Zhang W, Zheng W, Chi Y, Xu M, Fang Y, Gessler A, Li M, Wang S (2017b). Thinning effect on photosynthesis depends on needle ages in a Chinese fir (Cunninghamia lanceolata) plantation. Science of the Total Environ ment 580: 900-906. - doi: 10.1016/j.scitotenv. 2016.12.036

Liu B, Liu Q, Daryanto S, Guo S, Huang Z, Wang Z, Wang L, Ma X (2018). Responses of Chinese fir and Schima superba seedlings to light gradients: Implications for the restoration of mixed broadleaf-conifer forests from Chinese fir monocultures. Forest Ecology and Management 5157: 419-420. - doi: 10.1016/j.foreco.2018.03.033

Ming A, Jia H, Zhao J, Tao Y, Li Y (2014). Aboveand below-ground carbon stocks in an indigenous tree (Mytilaria laosensis) plantation chronosequence in subtropical China. PLoS One 9(10): e109730. - doi: 10.1371/journal.pone.0109 730

Ming A, Yang $\mathrm{Y}$, Liu S, Wang $\mathrm{H}$, Li Y, Li H, Nong $\mathrm{Y}$, Cai D, Jia H, Tao $Y$, Sun D (2018). Effects of near natural forest management on soil greenhouse gas flux in Pinus massoniana (Lamb.) and Cunninghamia lanceolata (Lamb.) Hook. plantations. Forests 9 (5): 229. - doi: 10.3390/f9050229 Omelko A, Ukhvatkina O, Zhmerenetsky A, Sibirina L, Petrenko T, Bobrovsky M (2018). From young to adult trees: how spatial patterns of plants with different life strategies change during age development in an old-growth Korean pine broadleaved forest. Forest Ecology and Management 411: 46-66. - doi: 10.1016/j.foreco. 2018.01.023

Ozbayram AK, Ciçek E (2018). Thinning experiments in narrow-leaved ash (Fraxinus angustifolia Vahl.) plantations: 10-year results. New Forests 49: 585-598. - doi: 10.1007/s11056-0189642-8

Petritan IC, Marzano R, Petritan AM, Lingua E (2014). Overstory succession in a mixed Quercus petraea-Fagus sylvatica old growth forest revealed through the spatial pattern of competition and mortality. Forest Ecology and Management 326: 9-17. - doi: 10.1016/j.foreco.2014.04. 017

Plath M, Mody K, Potvin C, Dorn S (2011). Establishment of native tropical timber trees in monoculture and mixed-species plantations: Smallscale effects on tree performance and insect herbivory. Forest Ecology and Management 261: 741-750. - doi: 10.1016/j.foreco.2010.12.004 Pommerening A (2002). Approaches to quantifying forest structures. Forestry 75: 305-324. - doi: 10.1093/forestry/75.3.305

Pommerening A, Särkkä A (2013). What mark variograms tell about spatial plant interactions. Ecological Modelling 251: 64-72. - doi: 10.1016/j. ecolmodel.2012.12.009

Potvin C, Dutilleul P (2009). Neighborhood effects and size asymmetric competition in a tree plantation varying in diversity. Ecology 90: 321327. - doi: 10.1890/08-0353.1

Pretzsch H, Del Río M, Schütze G, Ammer C, Annighöfer P, Avdagic A, Barbeito I, Bielak K, Brazaitis $G$, Coll L, Drössler L, Fabrika M, Forrester DI, Kurylyak V, Löf M, Lombardi F, Matovic B, Mohren F, Motta R, Den Ouden J, Pach M, Ponette Q, Skrzyszewski J, Sramek V, Sterba H, Svoboda M, Verheyen K, Zlatanov T, BravoOviedo A (2016). Mixing of Scots pine (Pinus sylvestris L.) and European beech (Fagus sylvatica L.) enhances structural heterogeneity, and the effect increases with water availability. Forest Ecology and Management 373: 149-166. doi: 10.1016/j.foreco.2016.04.043

R Development Core Team (2019). R: a Language and Environment for Statistical Computing. R Foundation for Statistical Computing, Vienna, Austria. [online] URL: http://www.r-project.org
Reed DD, Burkhart HE (1985). Spatial autocorrelation of individual tree characteristics in loblolly pine stands. Forest Science 31 (3): 575 587. [online] URL: http://academic.oup.com/for estscience/article-abstract/31/3/575/4656995

Sheng W (2001). A study on stand density management and long term productive of Chinese fir (Cunninghamia lanceolata) plantation. Scientia Silvae Sinicae 37 (5): 2-9. [online] URL: http://en.cnki.com.cn/Article_en/CJFDTotal-LYK E200105001.htm

Sheng W, Xue X (1992). Comparisons between pure stands of Chinese fir, Fukiencypress and mixed stands of these two species in growth, structure, biomass and ecological effects. Scientia Silvae Sinicae 28 (5): 397-404. [online] URL: http://en.cnki.com.cn/Article_en/CJFDTot al-LYKE199205001.htm

Sun D, Wen Y, Luo Y, Li X, Zhang W, Ming A (2015). Effect of close-to-nature management on species diversity in a Cunninghamia lanceolata. Forest Research 28 (2): 202-208.

Taki H, Inoue T, Tanaka H, Makihara H, Sueyoshi M, Isono M, Okabe K (2010). Responses of community structure, diversity, and abundance of understory plants and insect assemblages to thinning in plantations. Forest Ecology and Management 259: 607-613. - doi: 10.1016/j.for eco.2009.11.019

Trentini CP, Campanello PI, Villagra M, Ritter L, Ares A, Goldstein G (2017). Thinning of loblolly pine plantations in subtropical Argentina: Impact on microclimate and understory vegetation. Forest Ecology and Management 384: 236-247. - doi: 10.1016/j.foreco.2016.10.040 Wang J, Yan Q, Lu D, Diao M, Yan T, Sun Y, Yu L, Zhu J (2019). Effects of microhabitat on rodentmediated seed dispersal in monocultures with thinning treatment. Agricultural and Forest Meteorology 275: 91-99. - doi: 10.1016/j.agrformet. 2019.05.017

Wang Q, Wang S, Xu G, Fan B (2010). Conversion of secondary broadleaved forest into Chinese fir plantation alters litter production and potential nutrient returns. Plant Ecology 209: 269278. - doi: 10.1007/s11258-010-9719-8

Wan P, Zhang G, Wang H, Zhao Z, Hu Y, Zhang G, Hui G, Liu W (2019). Impacts of different forest management methods on the stand spatial structure of a natural Quercus aliena var. acuteserrata forest in Xiaolongshan, China. Ecological Informatics 50: 86-94. - doi: 10.1016/j.ecoinf. 2019.01.007

Wiegand T, Moloney KA (2014). A handbook of spatial point pattern analysis in ecology. Chapman and Hall/CRC press, Boca Raton, USA, pp. 47-77.

Wu Z, Zhou C, Zhou X, Hu X, Gan J (2018). Variability after 15 years of vegetation recovery in natural secondary forest with timber harvesting at different intensities in southeastern China: community diversity and stability. Forests 9 (1): 40. - doi: 10.3390/f9010040

Xiong Y, Sheng W, Zeng M (1995). A study on the development and biomass of undergrowth vegetation in Chinese fir plantation with different thinning intensities. Forest Research 8 (4): 408-412. [online] URL: http://europepmc.org/ article/cba/283448

Yao X, Li Y, Liao L, Sun G, Wang H, Ye S (2019). Enhancement of nutrient absorption and inter- 
specific nitrogen transfer in a Eucalyptus urophylla $\times$ Eucalyptus grandis and Dalbergia odorifera mixed plantation. Forest Ecology and Management 449 (1): 117465. - doi: 10.1016/j.for eco.2019.117465

Ye S, Zheng Z, Diao Z, Ding G, Bao Y, Liu Y, Gao G (2018). Effects of thinning on the spatial structure of Larix principis-rupprechtii plantation. Sustainability 10 (4): 1250. - doi: 10.3390/su100 41250

Zhang H, Zhou G, Wang Y, Bai S, Sun Z, Berninger $F$, Bai $Y$, Penttinen $P$ (2019). Thinning and species mixing in Chinese fir monocultures improve carbon sequestration in subtropical China. European Journal of Forest Research 138: 433-443. - doi: 10.1007/s10342-019-01181-7 Zheng Y, Chen L, Hong W (1998). Study on productivity and soil properties of mixed forests of Chinese fir and Phyllostachys heterocycla cv. pubescens. Scientia Silvae Sinicae 34 (1): 16-23. Zheng Y, Zhao W, Zhang G (2017). Spatial analysis of a Haloxylon ammodendron plantation in an oasis-desert ecotone in the Hexi corridor, Northwestern China. Forests 8 (6): 200. - doi: 10.3390/f8060200

\section{Supplementary Material}

Fig. S1 - The tree points, distribution patterns of the $C$. lanceolata and $M$. macclure in the mixed forest (MF) and their spatial correlations at the beginning of planting (1993).

Fig.S2 - The NND of the M. macclurei in the mixed forest (MF) during the management period (1993-2018).
Fig. S3 - The tree points of the six main populations in the mixed forest (MF) over a rotation of 27 years.

Fig. S4 - The tree points of the six main populations in the thinned forest (TF) above a rotation of 27 years.

Fig. S5 - The plants in the thinned forest (TF) and mixed forest (MF).

Tab. S1 - The quantitative characteristics of the main trees species in the thinned forest (TF) and mixed forest (MF).

Link: Li_3489@supploo1.pdf 